\title{
Casa como elemento do parentesco em duas localidades no Sul do Brasil
}

\author{
Raquel Wiggers ${ }^{1}$ \\ Universidade Federal do Amazonas
}

Resumo: Apresento duas etnografias onde a casa e as formas de morar definem relações sociais locais. Uma é uma comunidade urbana na periferia de Florianópolis (SC) pesquisada na década de 1990; a outra é uma localidade rural no sul da Ilha de Santa Catarina. A análise de casas inspirada em trabalhos de antropólogos como Lévi-Strauss, Bestard e Pina-Cabral, foi central para compreender a dinâmica e a organização social dos dois locais das pesquisas. Cada um a seu modo acionam noções de casa e morar.

Palavras-chave: casa; parentesco; organização social. 


\title{
Household as an element of kinship in two locations in southern Brazil
}

\begin{abstract}
It is presented two ethnographies where the home and ways of living define local social relationships. One is an urban community on the suburb of Florianópolis surveyed in the 9o's the other is a rural location in the south of Santa Catarina Island. The analysis of household was inspired by the work of anthropologists such as Lévi-Strauss, Bestard and Pina Cabral, and placed a central role in understanding the dynamics and social organization of the two research sites. Each in their own way trigger notions of home and living.
\end{abstract}

Keywords: Home; household; kinship; social organization.

\section{Casa como elemento de parentesco en dos localidades del sur de Brasil}

\begin{abstract}
Resumen: Presento dos etnografías donde la casa y las formas de habitar definen las relaciones sociales locales. Una es una comunidad urbana en la periferia de Florianópolis investigada en los años 90 y la otra es una localidad rural en el sur de la isla Santa Catarina. El análisis de casas inspirado en el trabajo de antropólogos como Lévi-Strauss, Bestard y Pina Cabral, fue fundamental para comprender la dinámica y la organización social de los dos sitios de investigación. Cada uno a su manera desencadena las nociones de casa y habitar.
\end{abstract}

Palabras-clave: casa; parentesco; organización social. 


\title{
As casas de minha pesquisa
}

$\mathrm{C}$ asa tem sido uma categoria de análise fundamental desde o trabalho de campo, em 1998, que resultou em minha dissertação de mestrado (WIGGERS, 2000), à época não tive ciência, imediatamente, da importância da casa como categoria central na análise de formas locais de resolução de conflitos domésticos. Na ocasião tratei como um dos elementos que o campo me trazia, sem me deter no conceito de casa e de morar. Foi em minha tese de doutorado, defendida em 2006 (WIGGERS, 2006), que a casa se tornou uma categoria central na análise do parentesco e pertencimento das pessoas à localidade rural no sul da Ilha de Santa Catarina.

Assim, já instrumentalizada pelos trabalhos anteriores, e sensível à importância da casa na organização social dos grupos humanos, iniciei trabalho de pesquisa em assentamentos rurais no sul do Amazonas e naquele contexto também pude perceber que olhar para as casas me iluminava e esclarecia muito da organização comunitária local. No entanto, neste artigo trago dados de duas etnografias que fiz no decorrer de minha trajetória acadêmica.

Diferentes formas de morar organizam as relações sociais de forma distinta e materializam aspectos particulares da cultura local. Resgato uma discussão de Pina-Cabral (1989; 1991) que ao estudar o Alto Minho em Portugal, conclui que

\begin{abstract}
um dos principais fatores que concedem unidade a uma visão de mundo é uma imagem do que, para aquela sociedade, é a unidade social primária, e a forma como se espera que essa unidade reproduza a si própria e se relacionem com outras unidades idênticas. (PINA-CABRAL, 1991: 110)
\end{abstract}

Para Pina-Cabral essa imagem deve estar subjacente às afirmações dos informantes sobre suas próprias sociedades, as unidades sociais primárias para serem assim consideradas precisam ter uma existência de longa duração e estar presente em todo tipo de manifestação cultural. A unidade social primária é designada na região do Alto Minho por três palavras: "casa", "família" e "lar", com usos e implicações distintos. Além disso, há uma distinção entre as palavras que utilizam os burgueses citadinos e os camponeses, os primeiros insistem no uso da palavra família, enquanto os camponeses enfatizam casa como representação da unidade social primária.

Nos dois contextos estudados e aqui apresentados, a referência à casa foi uma constante, mesmo que convivesse com referências à família e ao parentesco. PinaCabral (1991) argumenta que se temos a noção de família favorecendo a observação de laços interpessoais como elementos da estrutura social, retirando o peso das relações residenciais e econômicas, temos a casa (household) fazendo o hiato entre as práticas de residência e as categorias de parentesco (Pina-Cabral, 1991). Para Pina-Cabral olhar para casas possibilita que os agentes individuais não sejam reduzidos ao papel de representantes das unidades residenciais produtivas da qual fazem parte, tornando mais complexo o jogo cruzado entre identidades e interesses que caracteriza toda a vida social².

${ }^{2}$ No entanto, o autor sugere utilizar o conceito de unidade social primária, porque esse é para Pina-Cabral um conceito puramente descritivo, e casa tem seus problemas por se identificar com os termos coloquiais usados em distintos lugares 
Estudei família e conflitos domésticos na comunidade Chico Mendes, em Florianópolis (SC), durante todo o ano de 1998. E nesse contexto, a casa foi essencial para acessar os conflitos familiares e as formas de resolução dos conflitos. Essa pesquisa que ora apresento, foi desenvolvida em contexto urbano, a outra pesquisa apresentada neste artigo foi feita na Caieira da Barra do Sul, uma localidade no sul da Ilha de Santa Catarina, pesquisada em 2001. Na época a localidade estava num processo de mudanças importantes de abertura de um mundo rural para o urbano, e que no entanto, mantinha-se fortemente relacionada com aspectos da ruralidade. Estudei pertencimento à localidade formulada a partir de categorias daqui e de fora elaboradas a partir do pertencimento ou não das pessoas às casas da Caieira. Nos dois contextos olhar para as casas como elemento constituidor do parentesco e da comunidade foi esclarecedor de como as relações sociais são organizadas e vivenciadas.

\section{Comunidade Chico Mendes}

A comunidade Chico Mendes fica às margens da via expressa que dá acesso à cidade de Florianópolis, capital do estado de Santa Catarina, nos limites do município de São José. Na comunidade residem prioritariamente camadas da população urbana de baixíssima renda que, como define Fonseca (1987) em trabalho nas vilas de Porto Alegre, poderiam ser chamados de subproletariado. Diferem de grupos operários por viverem de biscates e de trabalhos esporádicos, da mendicância, de juntar papelão e metais para reciclagem e da recuperação do lixo das casas mais abastadas. São principalmente pessoas que na maior parte do tempo não estão incluídas no mercado formal de trabalho. Geralmente recebem muito pouco por suas atividades laborais, o que colabora para viverem pobremente.

Em 1998, a comunidade era organizada em forma de "lotes" com caminhos estreitos, calçados de cimento ligando cada um deles. Em cada "lote" havia vários barracos que eram construídos de alvenaria, madeira, papelão, telhas ou tudo isso junto. Algumas construções que inicialmente eram mais bem estruturadas e com quintais, foram divididas em diferentes casas. Podíamos encontrar casas de alvenaria de dois andares, concluídas e pintadas, ao lado de outras de madeira muito velhas e quase caindo, escoradas por troncos de madeira. Todas as casas que eu conheci tinham banheiro com um vaso sanitário e uma pia, e uma instalação para chuveiro. Estes banheiros foram construídos durante a obra de fornecimento de água e instalação de esgoto pela CASAN3 para todas as casas da Chico Mendes. Outra característica da comunidade é o fato de haver energia elétrica em todas as casas, providas pela CELESC4, não sendo necessário o uso de ligações clandestinas, o que é bastante comum nas comunidades pobres das periferias das cidades. Apesar das casas contarem com energia elétrica, os caminhos não foram iluminados.

Para se falar em família na comunidade Chico Mendes é necessário fazer uma referência à casa, posto que é um conceito fundamental na definição espacial da família nuclear. Segundo Woortmann (1982), a casa é onde se realiza o projeto de ter uma família, permitindo a realização dos papéis centrais na organização familiar, o de pai de família e o de mãe dona-de-casa. Este padrão ideal pressupõe o papel masculino de prover teto e alimentos do qual se orgulham os homens. Sarti (1996: 42), ao estudar famílias pobres, faz menção à divisão entre casa e família,

para referir-se a coisas distintas, o que dificultaria a comparação. No entanto, neste trabalho, levo em consideração o alerta de Pina-Cabral para atentar-me a apenas comparar o que é possível ser comparado, mas considero que o conceito de casa é muito útil para análise e nos permite olhar para os dois contextos etnográficos de forma comparativa.

3 Companhia Catarinense de Água e Saneamentos - CASAN.

${ }_{4}$ Centrais Elétricas de Santa Catarina S.A. - CELESC. 
em que cada uma é remetida a gêneros diferentes: ao homem cabe a família; e a casa é identificada com a mulher. Casa e família, como mulher e homem, constituem um par complementar, mas hierárquico, no que se refere à autoridade dentro de casa e, automaticamente, dentro da família nuclear. A família compreende a casa e que está, portanto, contida na família, mas o poder é hierarquizado e ao homem cabe maior poder de intervenção (SARTI, 1996).

Por sua vez, Sarti (1996) também percebeu, entre a população que estudou nos bairros residenciais pobres de São Paulo, que a moradia é fundamental para formação de uma nova família, e esta necessidade é expressa pelo ditado: "quem casa quer casa”. Na Chico Mendes é possível perceber a necessidade da casa para a constituição da família. É comum cada novo casal morar em uma casa separada com seus filhos, mesmo sendo apenas um cômodo da antiga residência dos pais. Nestes casos, o imóvel inicial é dividido segundo a necessidade das novas famílias que vão se formando, e geralmente só ocorre quando o casal tem seu primeiro filho. O nascimento do primeiro filho é um marco importante porque faz a "comunidade" considerar o novo casal como uma família.

Quando o imóvel dos pais, a ser dividido entre os filhos casados, tem mais de um cômodo, um deles pode ser separado do resto da residência fechando-se a porta interna e abrindo-se outra para a rua. Algo semelhante ocorre quando o imóvel inicial tem apenas um cômodo, mesmo assim ele pode ser dividido quando os filhos formam outra família. Nestes casos, uma parede é erguida no meio do único cômodo que compõem a casa e abre-se uma porta para a rua, fez-se uma nova residência. Uma outra possibilidade de se fazer casa é quando os pais saem da casa e vão morar em outro lugar, deixando a casa para ser dividida entre os filhos casados e com filhos. Essas casas e lotes serviam assim, a mais de uma família nuclear tornando os parentes, principalmente os irmãos e irmãs, sogros, cunhados e cunhadas e sobrinhos, também vizinhos. Estas novas casas são consideradas propriedades dos novos moradores, mas as regras de vizinhança e o convívio próximo, possibilitam e promovem interações frequentes e constantes. As habitações tinham a característica de colocarem em contato próximo famílias ligadas entre si por laços de consanguinidade e afinidade.

Algumas vezes encontramos um imóvel dividido em diversas casas, e nelas morando famílias não aparentadas entre si, isso acontece porque cada casal proprietário da casa pode vender ou negociar segundo seus interesses. Assim, em algumas casas as famílias vizinhas eram "estranhas".

Em nosso estudo sobre conflitos domésticos foi essencial elaborar as categorias locais de parentesco, que são fundamentais na definição de casa, são elas: "mais do que parentes", "parentes", "estranhos", como veremos a seguir.

Quadro: Categorias de referência de parentesco Fonte: (WIGGERS, 2000: 48)

\begin{tabular}{|c|c|c|c|}
\hline "Mais do que parentes" & "Parentes" & \multicolumn{2}{|c|}{ "Estranhos" } \\
\hline $\begin{array}{c}\text { Filhos, irmãos, cônjuges, mãe, } \\
\text { pai (desde que morando na } \\
\text { mesma casa) }\end{array}$ & $\begin{array}{c}\text { Tios(as), primos(as), irmãos } \\
\text { casados(as), cunhados(as), } \\
\text { sogros. E entre as mulheres: } \\
\text { as concunhadas }\end{array}$ & $\begin{array}{c}\text { "Vizinhos": pessoas não } \\
\text { parentes que moram nas } \\
\text { casas próximas }\end{array}$ & $\begin{array}{c}\text { Pessoas conhecidas } \\
\text { que moram na } \\
\text { comunidade }\end{array}$ \\
\hline
\end{tabular}


é composta pelos papéis familiares de filhos, mãe, pai, esposa e marido. Foram raras as casas em que os moradores eram outros, que não o casal com os filhos. As exceções eram: uma família que alugava quartos para homens sozinhos em caráter temporário; duas casas em que moravam também o pai da esposa e o irmão solteiro da esposa; e por fim, uma última casa, em que a dona era viúva, onde moravam alguns netos dela e um filho casado com sua esposa. Mesmo nessas casas, os "mais do que parentes" continuavam a ser aqueles já citados.

Para caracterizar os "parentes" é necessário inicialmente uma referência à proximidade de moradia. Os parentes que residem próximos da unidade doméstica são os mais facilmente lembrados quando se pergunta sobre parentesco. Ser "da família" é definido em primeiro lugar pelos membros residentes na casa, logo depois fazem referência aos parentes que moram próximos e, por fim, quando perguntados, "lembram" de pais e irmãos que moram em outra cidade. Víctora (1998) constatou o mesmo fenômeno entre a população que estudou em uma vila porto-alegrense. Essa autora acrescentou ainda que em seu estudo percebeu que o grupo familiar não permanece junto apenas por motivos materiais, em que a parentela se socorre mutuamente nos momentos de necessidade, mas é recorrente o grande valor que tem a família e a rede de reciprocidade. Assim, os parentes consanguíneos são: os irmãos casados, tios e tias, primos e primas, sobrinhos e sobrinhas, e avós.

Entre os afins é preciso ressaltar que nem todos com quem são estabelecidos laços de afinidade e nem todos os consanguíneos do cônjuge são considerados parentes. Em meu diário de campo registro uma ocorrência ilustrativa: uma vez chegou um menino de uns nove anos junto com as crianças de Rose e perguntei se aquele era dela também, ao qual ela respondeu que não de forma enfática. Disse que tem uns parentes do marido que moram perto e o menino é um primo dele. A referência a considerar os parentes do marido como "seus" foi repudiada com vigor. Em outro caso perguntei a Olímpia, se ela tinha parentes morando perto e ela disse que não. Eu perguntei: e o teu marido, tem? Ela me respondeu que ele tinha umas primas morando ali em cima. Neste caso elas eram parentes apenas do marido. Embasada nesta fala e em dados etnográficos, concluí que são considerados parentes por afinidade os cunhados e os sogros, e no caso feminino as concunhadas.

E por fim, há uma terceira categoria usada quando se pergunta sobre parentesco: os "estranhos". Ela não classifica diretamente quem são os parentes, mas deixa claro quem não o são, e desta forma define pela negativa algumas posições que ficam excluídas das combinações possíveis das relações de parentesco. Esta é uma categoria usada por diferentes pessoas do local para designar quando uma pessoa não é considerada parente, e que com ela não são estabelecidas relações como as de parentesco. Por sua vez, não são pessoas desconhecidas e sim seus vizinhos e pessoas que se encontram nas ruas, nas reuniões da ONG Tecendo Vidas, que atua na comunidade, nos postos de saúde, na escola ou em outros lugares públicos da comunidade.

Obtive esclarecimentos sobre esta categoria durante uma conversa em um beco com quatro mulheres e eu, quando perguntei: "Aqui mora parente?" - fazendo referência a uma casa em que estávamos encostados, já que ficamos na ruela todo o tempo. Responderam: "não, aqui não mora parente, aqui mora estranho". Eu olhei como se não tivesse entendido e Creonice me esclareceu: "É! São vizinhos, e vizinhos não são estranhos, mas não são parentes”. A vizinha em questão era dona Maribel, uma mulher forte, um pouco gorda, que logo veio juntar-se a nós, pegou um banquinho para sentar-se ao meu lado e ficou tentando ler o que eu escrevia. Ela foi 
casada com o pai do marido de Rose (cunhada de Creonice), mas isso não a fez parente, ela é "estranha".

No quadro apresentado é possível perceber que a categoria "estranhos" foi dividida em duas outras, na primeira estão os vizinhos e na segunda outras pessoas conhecidas que moram na comunidade. Fez-se relevante esta distinção porque nos casos de conflitos domésticos, há a possibilidade de intervenção da parentela, porém muitas das famílias estudadas não contam com parentes morando por perto, por terem vindo de outra cidade. Nestes casos, que não é possível a intervenção direta dos parentes, há a recorrência a outras instâncias. Geralmente são os vizinhos os primeiros a obterem permissão para a intervenção. Esta não se configura da mesma forma como aquela dos parentes, mas dá um respaldo social, ou não, às queixas públicas advindas do conflito doméstico.

Temos assim que, na comunidade estudada, as relações de parentesco são definidas por "laços de sangue" prioritariamente, e por alguns laços de afinidade, principalmente entre mulheres. Acredito que seja, senão impossível, ao menos muito raro tornar-se parente por relações de "amizade", ou por arranjos domésticos alternativos. No caso de Renata, uma moça criada desde menina por uma família do local, ela chama a mulher que a criou de madrinha e diz ser como uma filha para ela, mas continua considerando sua "família de sangue" como o estabelecedor de suas relações de parentesco, e os filhos de sua madrinha não são considerados seus irmãos.

Os parentes estão imbuídos de poder para resolver as questões fora do núcleo conjugal, e por que é importante pensar em termos de unidade doméstica? Porque além de ser esta uma unidade econômica e de reprodução, há um aspecto essencial para que neste trabalho seja feita esta distinção, e está relacionada com situações de conflito resolvidas dentro do espaço da casa, onde residem os "mais que parentes". Foi constatado em campo que em alguns casos as agressões físicas, ocorridas entre esposos, pais e filhos, são mantidos no espaço da casa, ou, para seguir a denominação utilizada anteriormente, entre "os mais que parentes".

Um fenômeno estava ocorrendo no fim de minha pesquisa de campo, no final do ano de 1998, na comunidade Chico Mendes: a prefeitura estava atuando na reurbanização da área. Algumas habitações da comunidade estavam sendo desmanchadas e estavam sendo construídas residências de alvenaria, pequenas de dois andares. Essas casas seriam sorteadas depois de prontas entre as famílias moradoras da comunidade. Por ocasião do início do processo de reconstrução da "favela", no projeto da prefeitura para "urbanizar" a área, foram escolhidos lotes contíguos, retiradas as famílias que foram realocadas num prédio provisório, e derrubadas todas as construções. Enquanto aguardavam a construção, as famílias desalojadas foram abrigadas em uma grande construção circular no centro da favela5. No entanto, as novas residências permanentes não eram em número suficientes para todas as famílias desalojadas, e algumas foram realocadas em conjuntos habitacionais populares construídos em outros bairros menos valorizados da cidade, a mais de 20 quilômetros da Chico Mendes.

Foram construídas casas coladas umas às outras, com as frentes um pouco mais para trás uma da outra, cada uma pintada de uma cor diferente, davam à comunidade um ar bonito de urbanidade. No entanto, o projeto que se iniciou em 1998 não alcançou todas as casas da comunidade, fazendo com que muitos lotes não tenham sido modificados.

Esse projeto de reurbanização mexeu com as estruturas familiares ao rearranjar os espaços das casas. E fez com que a Chico Mendes ficasse muito mais 
"perigosa" para moradores e frequentadores por causa da intensificação do tráfico de drogas violento na comunidade. Antes havia um espaço no centro da comunidade com dois campinhos de futebol, onde os jovens se reuniam para conversar, beber, e às vezes consumir e vender drogas. $\mathrm{O}$ tráfico de drogas era uma realidade presente na comunidade, no entanto havia um esforço das famílias em manter os filhos longe das drogas e do tráfico (WIGGERS, 2000). Os jovens estavam sob controle da família, dos "mais que parentes", dos parentes e algumas vezes dos vizinhos, que podiam fofocar aos pais o que os moços e moças estavam fazendo.

Por ocasião da reurbanização as casas novas foram sorteadas entre as famílias que haviam sido retiradas de suas casas originais. No sorteio não se respeitou a ordem anterior da vizinhança, foi um sorteio que colocou as famílias nas novas residências de forma aleatória. Os parentes não eram mais os vizinhos, provocando um desequilíbrio na organização e controle social dos jovens que antes havia. Quebraram-se redes de ajudas entre mulheres, parentas e vizinhas, redes de controle social das crianças e jovens. Isso fez com que a violência e o tráfico de drogas violento tomasse conta da favela. Os moços e moças já não estavam sob controle social dos parentes, estavam livres para serem absorvidos como mão de obra desqualificada e descartável que o tráfico de drogas precisa. Assim, o lugar ficou com uma bela aparência de urbanidade, com casas pintadas de colorido, todas iguais, harmônicas esteticamente, mas em total caos social.

\section{Caieira da Barra do Sul}

No ano de 2002 desenvolvi pesquisa na localidade Caieira da Barra do Sul à beira mar no extremo sul da Ilha de Santa Catarina, em Florianópolis. Neste lugar foi onde houve o primeiro povoado, no século XVII, nas terras ao Sul do Brasil, quando espanhóis e portugueses exploravam a região e as baías de águas calmas entre a Ilha e o continente eram propícias para abastecimento e conserto dos navios que ali chegavam avariados.

Meu interesse nessa pesquisa foi analisar as relações familiares e como se constituíam os processos identitários e territoriais, que em outras localidades da cidade acionavam a identidade de descendentes de açorianos ${ }^{6}$ (FANTIN, 2000; PEREIRA e PEREIRA, 1991; WIGGERS, 2006; 2007). Para minha surpresa, na Caieira não se diziam açorianos, mas acionavam categorias daqui e de fora como estruturais para marcar o pertencimento à localidade, sendo que ambas as categorias são construídas em referência ao pertencimento a uma casa da Caieira.

Assim, a categoria chave na minha análise de pertencimento à Caieira da Barra do Sul foi a casa, que aglutina família conjugal, família extensa, gerações diferentes e parentela. Uma casa na Caieira da Barra do Sul é um conjunto residencial composto por (1) várias habitações, em que o padrão de residência entre os moradores daqui é uma habitação servir a uma família conjugal composta de um casal casado e seus filhos solteiros. Em cada residência a família conjugal é o centro da organização doméstica, sendo responsável pelo sustento de seus membros e preparo da comida. Na casa, que é a soma das habitações e o terreno onde se encontram, (2) moram principalmente pessoas de uma mesma família extensa (3) de gerações diferentes.

Quando o pai (e/ou a mãe) ou o avô (e/ou avó) é proprietário do terreno onde mora, ou de parte dele, os filhos e netos, ao casar ou para casar, podem receber

${ }^{6}$ Açorianos diz respeito aos descendentes de migrantes das ilhas de Açores, que vieram para o litoral do Sul do Brasil no século XVIII. 
autorização para construírem ali as suas habitações. Este dono da casa, mesmo que não tenha poder absoluto de decisão sobre a propriedade, tem função de aglutinar a família em torno de si e da casa. Assim, a casa é composta por habitações onde reside o dono mais velho (homem ou mulher), e seus filhos e netos casados com seus respectivos cônjuges e filhos solteiros, cada família nuclear em uma habitação separada, e que, no entanto, são construídas próximas uma das outras.

É este sujeito aglutinador que garante a unidade da casa, porque enquanto ele viver a casa dificilmente vai ser dividida. Quando ele morrer a configuração da casa passará a ser outra e pode se desmembrar, com cada casal de uma geração imediatamente mais jovem que o antigo sujeito aglutinador formando a sua própria casa, separada da dos irmãos que antes viviam juntos na mesma casa.

Em cada casa sempre há uma pessoa, geralmente idoso, que faz o papel de aglutinar outros moradores em torno de si e de certa forma é ele quem dá unidade à casa. Eu os chamei de sujeitos aglutinadores. Talvez seja possível fazer uma comparação do sujeito aglutinador com o que Fortes (1950) chamou de headship, que eu traduziria pela expressão: dono da casa. Na Caieira, o arranjo doméstico sofre modificações se o sujeito aglutinador da Casa é um homem ou uma mulher. Uma mulher sozinha apenas será sujeito aglutinador de sua Casa quando for "velha" e viúva. Em torno da pessoa dela que se organizarão as famílias dos filhos. Um homem sozinho, por sua vez, só será o sujeito aglutinador da sua Casa se houver uma mulher (esposa, filha, prima) que faça as tarefas domésticas femininas. Um homem quando fica sozinho fica completamente desamparado e é enviado para a casa de um filho ou outro parente. O sujeito aglutinador masculino é, necessariamente, o casal, enquanto o feminino também é o casal, só que com marido morto.

No caso de dona Aparecida, ela faz o papel do sujeito aglutinador da sua Casa, é ela quem age como tal, porque (1) ela é proprietária dos terrenos que seus filhos vão herdar depois de sua morte, e sendo assim, é ela quem dá a palavra final sobre o que vai ser feito do terreno e das habitações construídas nele. Geralmente uma mulher ou homem viúvos têm diminuídos seus poderes de decisão sobre a terra que possuem, e seus filhos passam a ter muito mais voz nas decisões sobre a venda ou não porque, depois da morte de um dos pais, os filhos são herdeiros da metade dos bens do casal.

Além disso, dona Aparecida, assim como os sujeitos aglutinadores de outras casas, costuma mediar os conflitos entre os diferentes moradores da sua casa, e todos lhe têm respeito. O convívio com seus netos durante toda a infância deles fez com que ao menos Morena lhe dedicasse um carinho especial, sentindo-se responsável por ela, se preocupando com a sua saúde e bem-estar. É em torno dela que os filhos, genros e nora organizam sua vida social. É em torno dela, como headship, que os filhos adultos com filhos adultos se concebem como uma unidade. Quando Aparecida falecer, sua casa, muito provavelmente, vai ser desmembrada em pelo menos duas outras, que são as propriedades das filhas casadas de Aparecida, que já têm filhos casados morando na casa de dona Aparecida.

Em termos teóricos, a casa na Caieira tem um aspecto estrutural na medida que ela é responsável pela estruturação das relações de parentesco no bairro, mas o sujeito aglutinador entra com elementos da prática na formulação da casa.

A casa agrupa pessoas que estão relacionadas entre si por relações familiares próximas e aqueles que fazem parte da família por relações de afinidade (no caso os cônjuges dos filhos). Nem todos que recebem permissão para construir sua habitação em uma casa são da família nuclear, uma vez que podem receber autorização para construir um antigo empregado ou um filho de criação, ou o sogro 
de uma filha - mesmo que sejam situações mais raras. Assim, outras pessoas, que não apenas os familiares próximos, podem compor a casa de uma determinada família. Temos assim que uma casa, apesar de poder ser, até certa medida, identificada com uma família, não pode ser por ela traduzida. O sogro da filha, entretanto, não pode dispor de sua propriedade - vendê-la ou alugá-la. E o caso de um empregado que construiu sua casa na propriedade dos patrões foi muito particular. O casal tinha três filhos e um deles, o mais velho, saiu de casa para estudar contra a vontade do pai que o queria ajudando no trabalho da lavoura, uma vez que a família tinha terra suficiente para sustentar toda família e necessitava de mão de obra. Um rapaz (na época com 14 anos) filho de família da Caieira com poucas terras brigou em sua casa e passou a morar com esta família, trabalhando na lavoura e sendo tratado quase como filho. Este moço ao se casar recebeu da viúva de seu patrão, que lhe tinha apreço, a permissão de construir uma casa em sua propriedade. No entanto, o local que lhe coube não foi dos mais valorizados, sua casa foi a única que eu vi construída lá no meio do morro longe da estrada. Com isso a viúva ajudava um rapaz de quem ela gostava, que lhes ajudou em outras ocasiões, e não provocava disputa entre ele e os herdeiros legais do terreno seus filhos - porque aquele não é um terreno valorizado economicamente hoje em dia.

Na Caieira da Barra do Sul, a casa não é local de residência de todos os filhos casados do dono de uma casa, porque todos, depois que se casam, podem escolher o lugar de moradia. É possível - e bastante comum - que parte dos filhos de uma casa passem a residir em outros bairros. Esta opção é dada aos jovens desde há muitas gerações. Seu Lu contou-me a respeito de pessoas que foram embora, na geração de seus pais, a procura de uma alternativa ao trabalho duro nas roças e uma vida com poucos confortos. Alguns deles voltaram depois de aposentados, outros não voltaram mais.

Algumas pessoas que foram embora não se tornaram parentes a serem lembrados. Os velhos, responsáveis pela lembrança e pela atualização do parentesco, não lembram bem dos jovens moradores da Caieira, no entanto esta "não lembrança" não está determinada exclusivamente por questões geracionais, mas está relacionada, sobretudo ao estado civil da pessoa a ser lembrada. Se um jovem é casado e decidiu viver na Caieira, ele com certeza entra no rol de pessoas que existem, por exemplo, para dona Aparecida. No entanto, alguém solteiro, ou que ao se casar foi morar em outro bairro vai sendo progressivamente "esquecido", seus filhos não são registrados na memória da comunidade.

O jovem casal tem total liberdade para decidir morar fora da unidade de residência dos pais. Suas opções são (a) morar na casa de seus sogros; (b) morar fora do bairro ou (c) alugar uma casa na Caieira ou comprar um terreno no bairro, separado do de seus pais ou sogros e construir sua residência. Esta última possibilidade é apenas hipotética, porque nunca ouvi falar de que tal tipo de arranjo pudesse perdurar, e duas podem ser as explicações de ordem prática para tal ocorrência: a primeira é porque os terrenos no bairro são muito caros e os casais jovens não têm dinheiro para tal despesa, outra explicação dada é porque os terrenos de seus pais são grandes o suficiente para construírem suas habitações nele. No entanto, existem outras motivações de ordem simbólica que são muito mais importantes e que estão relacionadas com a necessidade de convívio dos membros da família extensa. O que pude constatar é que às pessoas casadas são dadas duas opções de escolha: (1) ou vão morar fora do bairro, (2) ou em uma residência construída na casa dos pais de um deles. As situações de residência fora dessas 
unidades são extremamente transitórias e excepcionais, e todos no bairro se mobilizam para que a situação logo se normalize, ajudando o casal na construção de sua casa no terreno dos pais de um deles.

As habitações construídas próximas favorecem as relações familiares cotidianas, tanto pela proximidade das residências quanto pela proximidade das relações sociais estabelecidas entre as pessoas que residem próximas. O contato entre o casal mais velho e seus filhos, seus genros e noras, e os netos, bem como entre os irmãos, cunhados, sobrinhos e primos são diários e intensos. As crianças são socializadas em uma grande família em que os primos convivem cotidianamente, muitas vezes sendo cuidados pela avó que se responsabiliza por eles enquanto as mães trabalham fora. A casa comporta diversas práticas que constroem a pessoa e marcam sua trajetória e sua pertença, entre elas o cuidado com as crianças, o cuidado com os idosos, a passagem entre as casas no caminho de sua própria casa, as trocas alimentares.

Também as relações entre membros da família extensa são intensificadas, entre famílias diferentes moradoras ou não da Caieira. Na casa convivem entre si os cônjuges dos diferentes filhos, e estes mantêm contato com suas famílias de origem. Isso possibilita que diversas famílias participem das redes de relações estabelecidas no bairro ou mesmo aquelas que se estendem para além do seu limite.

Assim, a casa favorece as relações e a convivência entre (1) gerações de uma mesma família, entre (2) pessoas de famílias diferentes e que são afins na casa em que escolheram morar, e também são (3) importantes na fundamentação da pertença daqueles que foram morar em outros bairros e que a atualizam no convívio familiar que mantêm com as pessoas que vivem na sua casa de referência na Caieira da Barra do Sul. É comum pessoas que morem em outros bairros da cidade e que atualizam constantemente suas relações com as pessoas que moram na Caieira e com a sua casa de origem. Isto faz com que compartilhem valores com os moradores nativos e que estejam integrados nas redes de sociabilidade do bairro. Além disso, o laço estabelecido com o lugar de nascença e onde se passou a primeira infância é considerado dos mais estreitos, dona Cecília me contou que sua sobrinha precisa ir aos Naufragados toda semana, "ela tem precisão dos Naufragados, diferente de seu irmão que não foi criado lá”. A filha de dona Ciça foi morar em um bairro perto do centro da cidade na juventude, lá casou e teve três filhas. Quando as filhas ficaram adolescentes ela mandou uma a uma ir morar com a avó na Caieira da Barra do Sul, o que fez que as moças se casassem com rapazes do lugar, estreitando suas próprias relações na localidade onde nasceu e onde mora sua família.

A casa, que é a soma de várias partes, é delimitada fisicamente pela extensão do terreno de propriedade dos membros da família extensa que a compõem. Porém suas relações sociais vão além da dimensão espacial - e esta pode ser a chave para pensar nas casas como fundamental para pertença e fazer a ponte entre a questão espacial e a classificação das pessoas. Na noção nativa de casa existem elementos fundamentais para pensar sobre pertença à Caieira da Barra do Sul, entre eles a importância dos laços sociais estabelecidos nas casas na elaboração da concepção de pessoa entre os moradores nativos, e o fato de cada casa ter algumas características morais que são atribuídas e compartilhadas por seus moradores, diferente da identidade açoriana que lhes é auferida de fora.

A casa de dona Aparecida mantém uma propriedade bastante vasta, com um terreno de aproximadamente 10 metros de frente que segue se alargando um pouco até as vertentes do morro. Assim, a casa tem grande parte de seu espaço físico ainda não ocupado por residências. O mesmo não se pode falar da casa de 
Seu Faberlúcio, que com a venda da maior parte da propriedade, inclusive da parte do morro onde fica a nascente de água, estende-se em um lote de aproximadamente 10x8om. No terreno com estas dimensões existem construídas 8 casas, colocadas de forma aleatória, sendo que para se chegar na casa de Seu Faberlúcio se passa na porta da casa de sua neta.

Este convívio é percebido como desejável e agradável. E existe uma rede de ajuda mútua que atua dentro da casa. Mariana, filha de Seu Faberlúcio cuida dos dois filhos da filha para ela ir trabalhar. A filha viúva de Mariana continua sendo a responsável pelo sustento das crianças, é ela quem as alimenta e veste, mas pode contar com o cuidado de sua mãe. O casal é responsável pelo sustento da sua unidade doméstica, e na falta de um dos cônjuges o outro torna-se o único responsável. Toda colaboração da família é percebida como ajuda e pode não ser constante.

Esta ajuda muito provavelmente será retribuída em outra ocasião, quando a própria Mariana precisar de cuidados. É a convivência da criança com os avós e tios que torna possível os laços importantes para que no futuro se tenha cuidado com os idosos. Uma moça falou emocionada que gostava muito do avô e cuidou dele com carinho por três anos que ele ficou de cama. É o convívio no grupo doméstico que possibilita que se estabeleçam relações afetuosas e de cuidado.

Idealmente os idosos são cuidados pelos familiares que vivem na casa. Um caso muito comentado entre diversas pessoas com quem conversei na Caieira, em julho de 2003, foi o de um homem de 60 anos, que vivia sozinho e que colocou a mãe no asilo. Havia uma recriminação geral com relação a sua atitude, principalmente pelo fato dele não ir visitá-la, e uma vez que a mãe veio para lhe fazer uma visita ele saiu de casa para não a receber. Alguns justificavam o fato dele tê-la colocado no asilo porque era homem e vivia sozinho, ele próprio estava doente com câncer e não podia cuidar da mãe. No entanto, o fato de não querer vê-la foi muito mal-recebido pela comunidade que o recriminava abertamente, inclusive argumentando que a causa de sua doença era o tratamento impróprio que auferiu a própria mãe. É comum a estratégia de manter a casa com aqueles que podem se cuidar, uns cuidando dos outros.

Apesar das relações dentro das casas serem idealmente harmônicas, esta não é a realidade sempre. Existem vários conflitos de diversas naturezas. Duas cunhadas que não se falam ou sogra e nora que se brigam abertamente. É o caso de Helena e sua sogra Mariana, ambas residem na casa de Seu Faberlúcio em casas separadas por um pequeno muro de tijolos vazados levantado depois que Helena ficou viúva e os ânimos se alteraram. Mariana acusa a nora de não ter sentido a morte do marido - seu filho. Brigam por causa do uso da água proveniente de uma única nascente e outros motivos diversos.

Este caso é interessante porque nos instiga a pensar do porquê de Helena não sair daquela casa. Ela não poderia vender sua casa e ir morar em outro lugar? Acredito que vários são os interesses que a motivam a ficar residindo na casa do avô do seu falecido marido. Um deles é manter a casa para seus próprios filhos. Como não foi feito o inventário da avó de seu marido, a proprietária legal da casa, que já faleceu há mais de 10 anos, seus filhos podem não receber sua parte da herança paterna, que está dividida apenas "de boca” (sem legalização). Além disso, os pais de Helena não têm casa na Caieira, são separados e bastante pobres, não têm condições de fornecer ajuda financeira ou em terras, nem uma estrutura de casa para ela e os filhos. Assim, mesmo não se dando bem com a sogra, suas crianças estão em contato com ela, com os primos da mesma idade, com os tios e 
outros parentes. E este é um contato valorizado por Helena, porque são as relações vivenciadas nas casas que vão estabelecer relações de parentesco, colaboração e cuidado mútuos no futuro.

As observações de campo me levaram a buscar em trabalhos etnográficos mecanismos teóricos para analisar o fenômeno da casa na Caieira. Quando casa deixa de referir-se ao imóvel e passa a ser uma categoria social, que vai além da dimensão espacial, pode ser apropriada em estudos de família e parentesco como uma importante unidade de análise. E este fenômeno é comum a uma gama de contextos etnográficos distintos. É o caso apontado por Klaas Woortmann (1982) em estudo em classes trabalhadoras brasileiras, que esclarece que a importância da casa vai muito além da dimensão de um 'teto sobre a cabeça'. Ela é crucial, não apenas de um ponto de vista material, óbvio, mas, igualmente, por constituir uma categoria central de um domínio cultural e um mapa simbólico de representações ideológicas (WOORTMANN, 1982: 119). A casa é pensada como a contrapartida material da família e é o lócus da realização do grupo doméstico.

No entanto, meu interesse é apontar para a importância que a casa assume na Caieira, com características que vão além do lócus de realização do grupo doméstico. Ela se estende para além desses aspectos. A casa é detentora de um domínio em que se configuram bens materiais e elementos imateriais como o cuidado com velhos e crianças, a idealização de um lugar bom para se viver, e é responsável pela relação estabelecida entre núcleos residenciais distintos.

Temos na Caieira grupos delimitados que poderiam ser definidos como famílias nucleares ou conjugais onde ocorre a reprodução humana e onde está a unidade de comensalidade, a lareira, o fogão. Apesar de ser o lócus de residência da família conjugal, esta não é a unidade básica de reprodução social. Esta ocorre em nível mais amplo, nas relações entre gerações diferentes de uma mesma família extensa.

\section{Unidades Sociais Primárias, Casas, Famílias}

Ao perceber a importância da noção de casa no contexto etnográfico da pesquisa na Caieira, o meu primeiro esforço foi buscar na proposta de Lévi-Strauss (1981) de societé a maison uma possibilidade de explicação desse fenômeno. Para Lévi-Strauss a sociedade de casas pode ser encontrada em diversos contextos, como uma mesma e única instituição: casa é uma pessoa moral detentora de um domínio composto simultaneamente por bens materiais e imateriais e que se perpetua pela transmissão do nome, da fortuna e dos títulos em linha real ou fictícia, tida como legítima sob a condição única de esta continuidade poder exprimir-se na linguagem do parentesco ou da aliança e, as mais das vezes em ambas ao mesmo tempo (LÉVI-STRAUSS, 1999: 3).

A casa, para Lévi-Strauss, é mais que espaço, é patrimônio e como tal tem uma certa autonomia sobre os indivíduos. A casa permanece e é no interesse de sua perpetuação que se transmite nomes, fortunas e títulos, impedindo a partição em cada geração.

A casa na Caieira, por sua vez, também é mais que espaço, é patrimônio e é responsável pela própria configuração das relações de parentesco. No entanto, a Caieira não pode ser analisada como societé a maison principalmente por causa da falta de continuidade da casa no tempo. A referência à casa da Minerva só existe porque dona Aparecida a vivenciou, mas ela não faz parte da experiência de sua neta, por exemplo. Portanto muito provavelmente passará a não existir mais depois da morte de dona Aparecida. Apesar desta característica, é possível 
falar que a casa na Caieira tem um aspecto estrutural, na medida que é fundamental na elaboração das relações de parentesco, estas sim perduram mesmo depois da casa acabar. É a casa que possibilita que haja relações entre parentes da forma como se configuram na Caieira. Por sua vez, na comunidade Chico Mendes, as casas estruturam as relações familiares de forma um pouco distinta, mas também não operam como patrimônios da mesma forma que operam na Caieira.

Rivière (1995) dá uma chave para pensar que há lugares onde não se pode tratar do conceito de casa de Lévi-Strauss, devido à perenidade das casas. Diz não estar seguro de que seja interessante separar conceito de casa e co-residência no grupo que estudou, e de certa forma, Rivière abre caminho para se buscar em outras referências o conceito de casa.

Carsten (2004) descreve o convívio na casa como fundador das relações de parentesco. No entanto, não concordo com sua abordagem, na medida que ela faz parecer que só o convívio cria um parentesco, aleatoriamente, sem que o resultado deste convívio não fosse culturalmente estabelecido e como se não houvesse algum nível de uma estrutura. Se fosse assim completamente aleatório, cada família teria uma organização familiar diferente. No entanto, na Caieira e na Chico Mendes, assim como no Alto Minho, estudado por Pina Cabral (1986), é possível se traçar constâncias na forma como as famílias vivem e como o conjunto de famílias se organiza socialmente.

A crítica da autora para a proposta de Lévi-Strauss de utilização da noção de sociedade de casas embasa-se no argumento de que este é um tipo de forma social primária que ocorre entre sociedades que são reguladas pelo parentesco e aquelas que operam por classe (CARSTEN, 2004: 42). E propõem que a noção de house quebra com a estrutura porque seu ponto de partida é a instituição social casa, que é entendida no seu contexto histórico e social.

Casa na Caieira é mais do que "um grupo que co-reside e desenvolve funções domésticas”, segundo a definição de household formulada por Bender (apud PINA CABRAL, 1991: 125). Ela tem relações próximas com a família, e principalmente, é na casa que a pessoa se identifica e se constrói como "daqui”. É a casa de referência na Caieira que possibilita as relações e identificações dos moradores atuais e dos parentes que foram embora para outros bairros e que, no entanto, atualizam sua pertença para que haja receptividade quando voltarem.

Bestard, em seu livro Parentesco y Modernidad (1998), nos traz exemplos de sociedades em que o conceito de casa pode ser aplicado como base para se estudar o parentesco e a organização social. Busca estes exemplos em trabalhos sobre o parentesco tradicional europeu e de sociedades rurais do mediterrâneo. Para Bestard (1998: 180), naquele contexto, o símbolo central da solidariedade duradoura é a união residencial, isto é,

a casa entendida como uma associação de pessoas a uma propriedade e um costume. A casa representa uma unidade social primária formada por uma unidade de parentesco, baseada na bilateralidade, e por uma unidade de residência e comensalidade, baseada em um fundo comum. (BESTARD, 1998: 180)

Pina-Cabral define unidade social primária como unidade socialmente construída de ação e apropriação do mundo, elaboradas a partir das categorias de identidade social. No entanto, é preciso atentar para a distinção entre identidades sociais que correspondem a unidades sociais ou não. Por exemplo, o gênero na Europa é categoria de identidade social, mas não corresponde a unidades sociais. Unidades sociais primárias são definidas como "nível de identidade social que tem maiores implicações estruturais na integração social das pessoas e na apro- 
priação social do mundo - nomeadamente, através da instituição do nível primário de autoridade formalmente reconhecido. Este será também o nível em que os participantes reconhecem a integração primária entre a reprodução social e a reprodução humana" (PINA CABRAL, 1991:118).

Segundo Pina Cabral (1991; 2003) o modelo de unidade social primária na Europa Mediterrânea e Atlântica deverá sempre considerar três vetores simbólicos de integração, presentes em todos, mesmo que a importância varie: a unidade do parentesco, manifestada através da filiação bilateral, cujo símbolo principal é o sangue; a unidade de residência, manifestada pela apropriação comum do espaço, simbolizada pela casa; e por fim a unidade de comensalidade, simbolizada pela lareira ou pelo fogo e o fogão. Mesmo que tenham valores diferentes em contextos culturais específicos dentro da Europa, estes três vetores mostram-se importantes nas análises de família. Para aplicar a noção de unidade social primária em outros agrupamentos humanos é preciso considerar quais os elementos eleitos como fundamentais naqueles contextos culturais específicos. Cada contexto cultural vai favorecer as bases para compor sua unidade social primária.

Segundo Bestard, diferente do que ocorre na Catalunã, Galicia e Vasco, a casa em Santa Maria del Monte (Behar,1986 apud Bestard,1998) não constitui um símbolo de continuidade no tempo, mas se divide da mesma forma que se divide a terra. Neste caso a unidade residencial é essencialmente um contexto, o da vida familiar. Por não perdurar não cria obrigações demandadas pelo passado, nem constituem o lugar da condensação da continuidade familiar. A casa não é igual a si mesma através das gerações, porque os fragmentos mudam de forma com a divisão dos bens por herança entre todos os filhos igualmente. $\mathrm{E}$ isto a faz não atuar como objeto autônomo que se superpõe às pessoas que residem nele. É o fato de viverem juntos que cria a obrigação de ajuda, uma dívida moral dos filhos para com seus pais. Estes têm que residir de maneira estável em uma casa com um dos seus filhos, que não devem forçá-los a circular entre várias casas.

Nas casas da Caieira é possível encontrar alguns dos elementos encontrados nos exemplos usados por Bestard, entre eles, o fato de a casa a que uma pessoa pertence ser um dos importantes elementos que a constituem. A própria afirmação de que alguém é de tal casa (não a casa pertencer a tal pessoa) demonstra uma pertença "invertida" que faz as pessoas pertencerem ao lugar que ancora suas práticas sociais. As pessoas pertencem ao lugar que praticam. E a casa representa uma herança espiritual e material também na Caieira da Barra do Sul, mesmo que ela não tenha grande duração, no sentido de permanecer fisicamente a mesma por várias gerações. A casa na Caieira é fluída e dura o tempo que durar a memória produzida por eventos importantes para as pessoas que conviveram e praticaram uma determinada casa. A memória do parentesco não é buscada muito longe na árvore genealógica avançando apenas duas ou três gerações acima de ego. Por isso é tão importante atualizar a pertença e o convívio cotidiano na casa. A prática do lugar é que vai fazer possível que o tempo cotidiano seja vivido como um tempo da eternidade.

No entanto, na Caieira, a casa é um patrimônio e a divisão da herança é um elemento importante na constituição dos laços familiares e na configuração da casa. Na comunidade a casa não tem qualquer aspecto de patrimônio, ela é apenas o elemento físico agregador do parentesco e da família, ela não tem durabilidade no tempo, é efêmera e por isso não representa aquele elemento que está acima dos indivíduos e que rege as relações que vão ser estabelecidas, os casamentos e filiações. Mas isso não desqualifica como elemento importante no parentesco, na organização estrutural da família, na delimitação de quem nutre, 
quem pode intervir nos conflitos, quem pode ser liderança da comunidade. $\mathrm{O}$ pertencimento que na Caieira está relacionado com a casa, na comunidade Chico Mendes está relacionado com a possibilidade de intervenção nos conflitos das famílias nucleares e também na organização espacial da comunidade.

O convívio nas casas formula o parentesco e cria obrigações de ajuda. É responsável também pelo desenvolvimento dos sentimentos de parentesco - de ter sido criado junto. A casa na Caieira é a unidade doméstica que se faz referência ao falar sobre o sentimento de pertencer à Caieira, além de ser um conceito do parentesco. Temos assim, que o próprio parentesco é formulado pelas emoções do "ser criado junto". Ao se falar de casa não se está falando de genealogias, mas de uma convivência e sentimentos promovidos pelo convívio está-se falando de emoções. A preocupação principal de Bestard (1998: 199) é mostrar que

\begin{abstract}
os símbolos de parentesco, longe de serem uma réplica das relações de consanguinidade, se formam a partir de domínios da realidade que adquirem a capacidade de denotar o princípio da solidariedade característica das relações de parentesco. A casa pode ser um destes símbolos na medida em que, nas etnografias europeias e mediterrâneas, constituem um ponto de referência a partir do qual não só se define o caráter solidário das relações de parentesco senão também suas qualidades.
\end{abstract}

Bestard defende, desta forma, uma análise do parentesco formulado com base em domínios da realidade que fundamentam a solidariedade característica das relações de parentesco. E a casa pode ser pensada como um lugar especial para a formulação destes sentimentos.

As casas dessa pesquisa são distintas daquelas definidas por Lèvi-Strauss, fundamentalmente porque elas são efêmeras. Na Caieira, por causa da divisão da herança igualmente entre todos os filhos, que divide a terra e a casa, durando o tempo de vida adulta de uma pessoa, e para além deste período, permanece apenas na memória daqueles que a vivenciaram. E na Chico Mendes elas são essencialmente efêmeras, podendo ser destruídas pelos projetos do Estado.

Recebido em 3 de outubro de 2020.

Aceito em 27 de novembro 2020. 


\section{Referências}

BESTARD, Joan. Parentesco y Modernidad. Barcelona: Paidós Ed., 1998.

CARSTEN, Janet. After Kinship. New York: Cambridge Press, 2004.

FANTIN, M. Cidade dividida. Dilemas e disputas simbólicas em Florianópolis. Florianópolis: Cidade Futura, 2000.

FONSECA, Cláudia. Mulher chefe de família. Revista de Ciências Sociais, 1 (2): 261$8,1987$.

FORTES, Meyer. “Introduction”. In: GOODY, Jack (ed.). The Developmental Cycle in domestic groups. London: Cambridge, (1950) 1971.

LÉVI-STRAUSS, Claude. Via das Máscaras. Lisboa: Ed. Presença/Martins Fontes, 1981.

LÉVI-STRAUSS, Claude. História e Etnologia. Textos didáticos, 24. IFCH/UNICAMP, Campinas, 1999.

PEREIRA, N. V.; PEREIRA, F. V.; SILVA NETO, W. J. Ribeirão da Ilha Vida e Retratos. Coleção Memórias de Florianópolis. Florianópolis: Fundação Franklin Cascaes, 1991.

PINA-CABRAL, João de. O homem na família: cinco ensaios de antropologia. Lisboa: Imprensa de Ciências Sociais, 2003.

PINA-CABRAL, João de. Os contextos da Antropologia. Coleção Memória e Sociedade, ed. Lisboa: Difel, 1991.

PINA-CABRAL, João de. Sons of Adam, Daughters of Eve: the peasant worldview of the Alto Minho. Oxford: Clareton Press, 1986.

RIVIÈRE, Pierre. "Houses, Places and Peoples: community and continuity in Guiana”. In: HUGH-JONES, Stephen; CARSTEM, Janet (orgs.). About the house: Lévi-Strauss and beyond. New York: Cambridge University Press, 1995.

SARTI, C. A. A família como espelho: um estudo sobre a moral dos pobres. São Paulo: Cortez, 1996.

VÍCTORA, Ceres. Agora me fala da tua família: uma abordagem etnográfica à estrutura familiar e à composição da unidade doméstica no Brasil e na Inglaterra. XXII Encontro Anual da ANPOCS, GT Sociedade e família, 1998.

WIGGERS, R. Família em conflito: violência, espaço doméstico e categorias de parentesco em grupos populares de Florianópolis. Dissertação de Mestrado, Antropologia, UFSC, 2000.

WIGGERS, R. "Sou daqui da Caieira da Barra do Sul”: parentesco, família, casa e pertença em uma localidade no sul do Brasil. Campinas, Tese de Doutorado em Ciências Sociais, Unicamp, 2006.

WIGGERS, R. Processo de desenvolvimento local e preservação ambiental em uma localidade no sul do Brasil. Ruris - Revista do Centro de Estudos Rurais, 2: 99-122, 2007. 
WOORTMANN, Klaas. Casa e Família Operária. Anuário Antropológico (80), 5 (1): 119-150, 1981.

ZALUAR, Alba; ALVITO, Marcos (orgs). Um século de Favela. Rio de Janeiro: Ed. Fundação Getúlio Vargas, 1998.
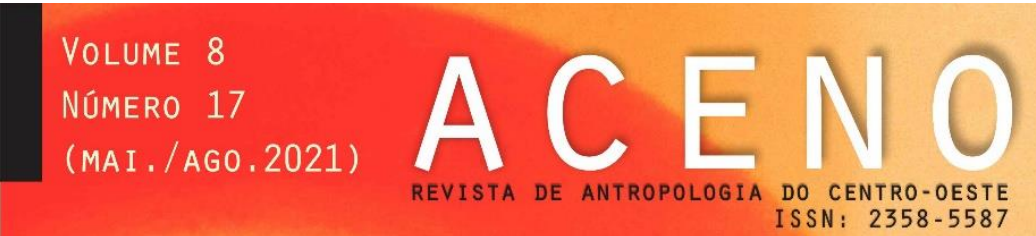

CHAMADA DE ARTIGOS

DOSSIE TEMÁTICO:

RETOMADAS E RE-EXISTÊNCIAS

INDÍGENAS, NEGRAS E QUILOMBOLAS

COORDENADORXS :

SONIA REGINA LOURENÇO (PPGAS/UFMT)

CAUÊ FRAGA MACHADO (NUPACS/UFRGS)

SANDRO JOSE DA SILVA (PGCS/UFES)

ste dossiê temático da ACENO tem como objeto as territorialidade e os processos de identificação negras, quilombolas e indígenas. A 1 proposta busca chamar a atenção para processos de identificação e territorialização que forneçam perspectivas adicionais às análises consolidadas que se dedicaram às tradições, à etnogênese e às situaçôes de fronteiras étnicas, mais afeitos às mediações com o Estado-nação, que privilegiaram as relações políticas, agentes e agência da burocracia.

Um movimento renovado de coletivos indígenas, quilombolas e negros tem revisitado tais abordagens mediante a crítica sistemática aos padrões eurocentrados, brancos e coloniais que produziram a invisibilização sistemática do que esses movimentos consideram relevantes. Dentre essas, categorias como "retomada" e "resistência" - não apenas como reação, mas como re-existir - territorial e existencial são fundamentais quando tomadas como conceitos que descrevem diferentes vínculos entre actantes dos mais diversos modos de existência.

A proposta privilegiará a publicação de etnografias e reflexões teóricas acerca desse novo cenário no qual entes produzem reflexões cosmopolíticas e modos de agir com (ou contra) o Estado-nação de modos antes insuspeitos. Espera-se que as contribuições contemplem a diversidade regional, étnicoracial e de gênero, bem como contribuições dos povos originários e povos e comunidades tradicionais.

PRAZO FINAL

DE SUBMISSÃO:

30 DE ABRIL

DE 2021 pela cosmologia e relacionalidade estendida a todos existentes,

identificações e territorialidades que encontram novas maneiras de se expressar, retomando terras, práticas, contato com seres, objetos, linguagens sem que essas nunca tenham sido perdidas de fato. 